\title{
Investigation on the preparation and properties of nanostructured cerium oxide
}

\author{
G. Jayakumar, A. Albert Irudayaraj*, A. Dhayal Raj, M. Anusuya \\ PG \& Research Department of Physics, Sacred Heart College, Tirupattur, Vellore District, \\ Tamil Nadu, India \\ *gjayaphysics@gmail.com
}

PACS 61.46.-W

DOI 10.17586/2220-8054-2016-7-4-728-731

Cerium oxide $\left(\mathrm{CeO}_{2}\right)$ nanoparticles were successfully synthesized by the hydrothermal method with different reaction times. The synthesized $\mathrm{CeO}_{2}$ nanoparticles were characterized by Powder X-Ray diffraction (XRD), Scanning Electron Microscopy (SEM), UV-Vis spectroscopy and FTIR spectroscopy. The effects of the reaction time on the structure and morphology of the prepared samples were investigated using XRD and SEM. The XRD studies reveal that the ceria nanoparticles have face-centered cubic structure. The SEM images reveal that the prepared Ceria nanoparticles are an aggregated form of spherical nanoparticles and the particle size decreases with increasing reaction time. FTIR analysis confirms the presence of $\mathrm{CeO}_{2}$ in the prepared samples. UV-Vis spectral studies show that the UV cut off wavelength decreases and the optical band gap increases with increased reaction time. Photoluminescence (PL) studies indicate that the PL emission of both the samples occurs at $683 \mathrm{~nm}$, however, the emission intensity increases with longer reaction times.

Keywords: ceria nanoparticles, hydrothermal method, photoluminescence.

Received: 8 February 2016

Revised: 10 May 2016

\section{Introduction}

Cerium oxide $\left(\mathrm{CeO}_{2}\right)$ is a refractory material possessing cubic fluorite crystal structure $[1,2]$. It is one of the most reactive rare earth metal oxides due to its oxygen storage capacity (OSC), oxygen deficiency, and electronic conductivity. It has promising applications in fuel cells, oxygen sensors and mechanical polishing. It also has utility as an ultraviolet blocking agent, luminescent material and photocatalyst. Ceria nanoparticles can be prepared by methods such as hydrothermal [3], reverse micelles, micro-emulsion [4], homogeneous precipitation [5] etc. The main objective of this research paper is studying the effect of reaction time on the structural and optical properties of nanostructured cerium oxide prepared by the hydrothermal method.

\section{Experimental}

\subsection{Synthesis}

All the reagents used in the synthesis process were of analytical grade purity and used without any further purification. In the synthesis process, $0.274 \mathrm{~g}$ of ammonium ceric nitrate $\left(\left(\mathrm{NH}_{4}\right)_{2} \mathrm{Ce}\left(\mathrm{NO}_{3}\right)_{6}\right)$ was dissolved in $5 \mathrm{ml}$ distilled water and $0.499 \mathrm{~g}$ of Sodium hydroxide $(\mathrm{NaOH})$ was dissolved in $25 \mathrm{ml}$ distilled water. These two solutions were mixed and the mixture was stirred for $30 \mathrm{~min}$. To the resultant precursor solution obtained, $0.1808 \mathrm{~g}$ of urea $\left(\mathrm{CO}\left(\mathrm{NH}_{2}\right)_{2}\right)$ dissolved in $10 \mathrm{ml}$ of distilled water, was added. The solution was transferred to a Teflon-lined autoclave which was maintained at $200^{\circ} \mathrm{C}$ for 24 hours. The autoclave was allowed to cool down naturally and to reach the room temperature. The final product was collected from the autoclave and washed several times with distilled water and ethanol. The product was dried at $80^{\circ} \mathrm{C}$ for 6 hours. The dried sample was calcined at $400^{\circ} \mathrm{C}$ for $2 \mathrm{hrs}$.

$$
\begin{gathered}
\mathrm{CO}\left(\mathrm{NH}_{2}\right)_{2}+3 \mathrm{H}_{2} \mathrm{O} \rightarrow 2 \mathrm{NH}_{4}^{+}+2 \mathrm{OH}^{-}+\mathrm{CO}_{2} \uparrow \\
\mathrm{NH}_{4}^{+}+\mathrm{OH}^{-} \leftrightarrow \mathrm{NH}_{3} \cdot \mathrm{H}_{2} \mathrm{O} \leftrightarrow \mathrm{H}_{2} \mathrm{O}+\mathrm{NH}_{3} \uparrow \\
\left(\mathrm{NH}_{4}\right)_{2} \mathrm{Ce}\left(\mathrm{NO}_{3}\right)_{6}+4 \mathrm{NaOH} \stackrel{200^{\circ} \mathrm{C}}{\longrightarrow} \mathrm{Ce}(\mathrm{OH})_{4}+4 \mathrm{NaNO}_{3}+2 \mathrm{NH}_{3} \uparrow+2 \mathrm{NO}_{3}+\mathrm{H}_{2} \uparrow \\
\mathrm{Ce}(\mathrm{OH})_{4} \cdot x \mathrm{H}_{2} \mathrm{O} \stackrel{80^{\circ} \mathrm{C}}{\longrightarrow} \mathrm{Ce}(\mathrm{OH})_{4}+x \mathrm{H}_{2} \mathrm{O} \uparrow \\
\mathrm{Ce}(\mathrm{OH})_{4} \stackrel{400^{\circ} \mathrm{C}}{\longrightarrow} \mathrm{CeO}_{2}+2 \mathrm{H}_{2} \mathrm{O} \uparrow
\end{gathered}
$$




\subsection{Characterizations}

The XRD measurements were carried out using Rigaku X-ray diffractometer with $\mathrm{CuK} \alpha(\lambda=1.54187 \AA)$ radiation in the range of $10-80^{\circ}$ at room temperature. The surface morphology of the particles was studied by scanning electron microscope.The optical transmittances of the samples were studied by Varian Cary 50 UV-Visible spectrophotometer in the range $200-800 \mathrm{~nm}$. The FTIR spectra were recorded in the range of $400-4000 \mathrm{~cm}^{-1} \mathrm{by}$ PERKIN ELMER SPECTRUM II FTIR spectrometer. The photoluminescence spectra were obtained by PERKIN ELEMER LS45 fluorescence spectrophotometer using excitation wavelength of $343 \mathrm{~nm}$.

\section{Results and discussions}

\subsection{XRD analysis}

The powder XRD patterns of $\mathrm{CeO}_{2}$ nanoparticles prepared with different reaction times are shown in Fig. 1. The peaks are indexed using JCPDS card \#34-0394. Both 12 hour and 24 hour $\mathrm{CeO}_{2}$ samples have Face Centered Cubic structure with lattice parameters $a=b=c=5.411 \AA$ and $\alpha=\beta=\gamma=90^{\circ}$. The diffraction peaks found at $28.27,33.09,47.34,53.36,69.26$ and $76.75^{\circ}$ showed a broadening effect, which suggests the formation of nanosized $\mathrm{CeO}_{2}$. The absence of impurities indicates that pure $\mathrm{CeO}_{2}$ is synthesized by the hydrothermal method. The average crystallite sizes $(D)$ of the $\mathrm{CeO}_{2}$ nanoparticles prepared with different reaction times, were calculated using the Debye-Scherrer equation:

$$
D=\frac{K \lambda}{\beta \cos \theta},
$$

where $\lambda$ is the wavelength of the $\operatorname{CuK} \alpha$ radiation, $\mathrm{D}$ is the crystallite size, $\mathrm{K}$ is a constant and its value is taken as $0.9, \theta$ is the diffraction angle and $\beta$ is the full-width half maximum (FWHM). The average crystallite size decreased slightly from $3.9 \mathrm{~nm}$ to $3.6 \mathrm{~nm}$ as the reaction time increased from 12 to 24 hours. The decrease of crystallite size with increasing reaction time was also confirmed from SEM images.

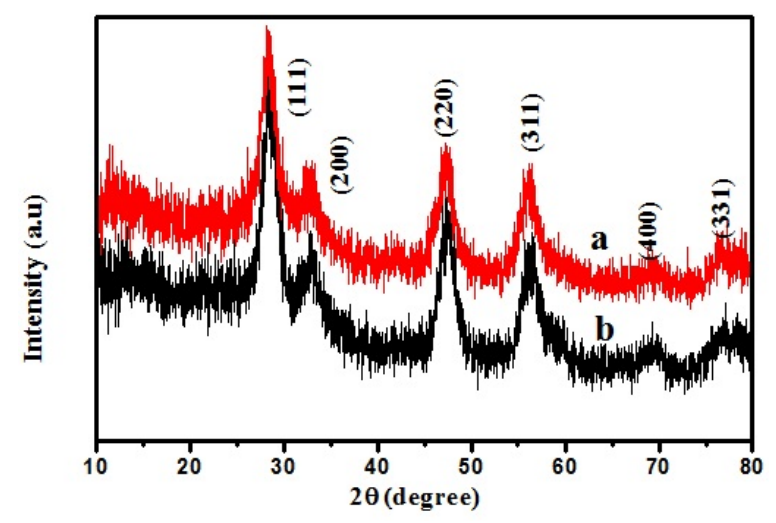

FIG. 1. XRD spectra of the $\mathrm{CeO}_{2}$ nanoparticles prepared at (a) 24 hours and (b) 12 hours

\subsection{FTIR spectra}

The FTIR spectra of $\mathrm{CeO}_{2}$ nanoparticles prepared by hydrothermal method with different reaction times are shown in Fig. 2. The band below $700 \mathrm{~cm}^{-1}$ is due to the $\mathrm{Ce}-\mathrm{O}$ stretching vibrations [6-8].

\subsection{UV-Visible spectra}

The optical properties of synthesized $\mathrm{CeO}_{2}$ were examined by UV-Visible spectrophotometer and the results are depicted in Fig. 3. The UV cutoff wavelength of the 12 hour sample was $349 \mathrm{~nm}$, while the UV cutoff wavelength of the 24 hour sample was $343 \mathrm{~nm}$. Additionally, the UV-Visible spectra showed no other peak related with impurities and structural defects, which confirmed that the synthesized nanoparticles are pure $\mathrm{CeO}_{2}$. The band gap energy of 12 hour sample was $3.54 \mathrm{eV}$, whereas the band gap energy for the 24 hour sample was found to be $3.67 \mathrm{eV}$. As the reaction time increased, the band gap energy increased while the crystallite size decreased. 


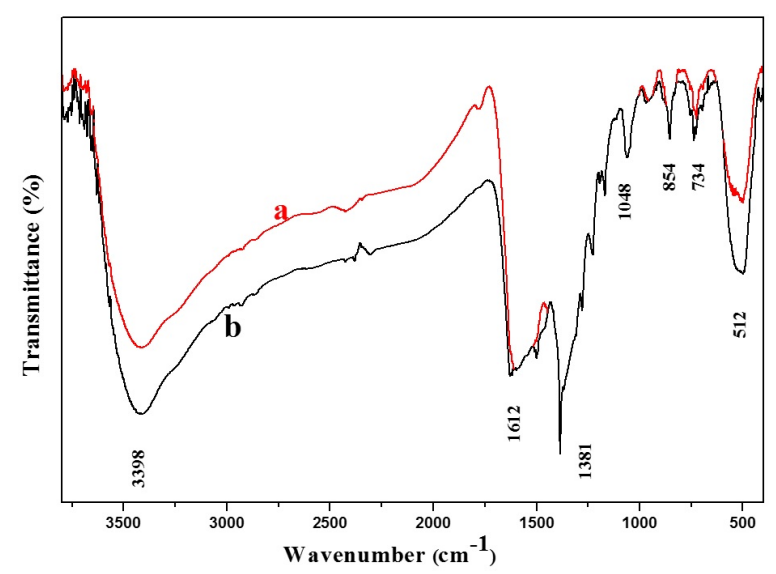

FIG. 2. FTIR spectra of the $\mathrm{CeO}_{2}$ nanoparticles prepared at (a) 24 hours and (b) 12 hours
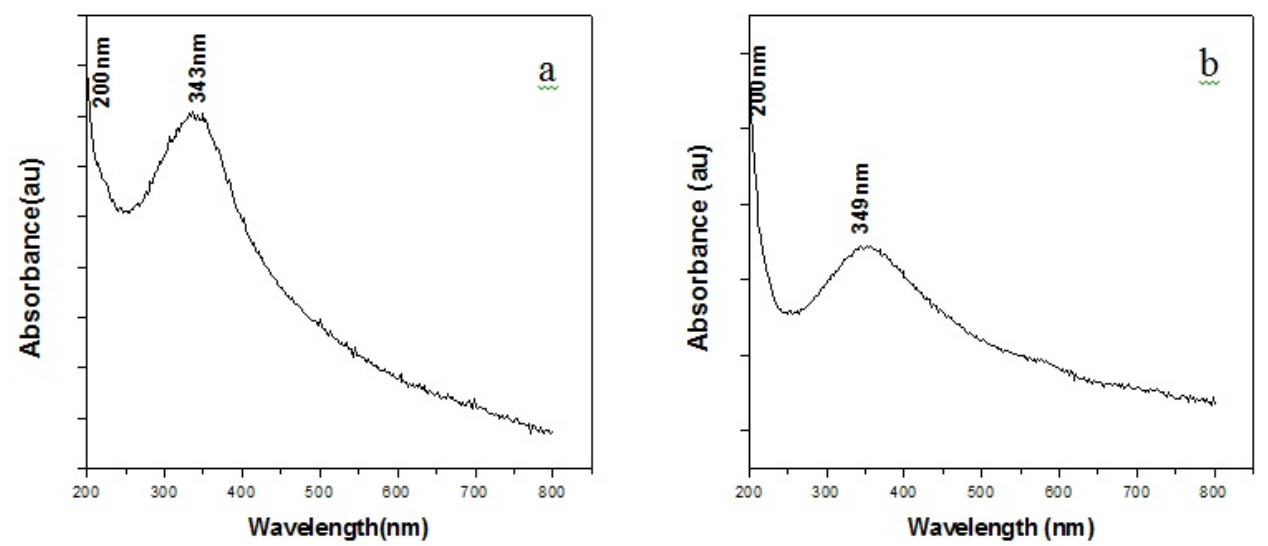

FIG. 3. UV-Vis spectra of the $\mathrm{CeO}_{2}$ nanoparticles prepared at (a) 24 hours and (b) 12 hours

\subsection{Scanning electron microscopy}

The SEM images of the $\mathrm{CeO}_{2}$ nanoparticles prepared by hydrothermal method with different reaction times are shown in Fig. 4. The $\mathrm{CeO}_{2}$ nanoparticles prepared with 12 hours reaction time had sphere-like structure with an average particle size of $78 \mathrm{~nm}$. The $\mathrm{CeO}_{2}$ nanoparticles prepared with 24 hours reaction time also had sphere-like structure with an average particle size of $63 \mathrm{~nm}$. Hence, it may be said that the change in the reaction time does not lead to any change in the shape of the $\mathrm{CeO}_{2}$ nanoparticles, however, the change in the reaction time definitely had an effect on the particle size. The particle size decreased with additional reaction time.

\subsection{Photoluminescence studies}

The PL spectra of the $\mathrm{CeO}_{2}$ nanoparticles prepared with different reaction time are shown in Fig. 5. The samples were excited by $343 \mathrm{~nm}$ wavelength, and the emission wavelength of these samples was obtained at approximately $683 \mathrm{~nm}$. This emission peak corresponds to red-light. The emission intensity increased from 110.8 a.u to 132.6 a.u with longer reaction times.

\section{Conclusions}

$\mathrm{CeO}_{2}$ nanoparticles were successfully synthesized by hydrothermal method and were analyzed by XRD, FTIR, SEM, UV-Visible spectroscopy and photoluminescence measurements. The studies indicate that the reaction time has an effect on the particle size and hence on the optical properties of $\mathrm{CeO}_{2}$ nanoparticles. The $\mathrm{CeO}_{2}$ nanoparticles prepared at 24 hours exhibited smaller particle size. The XRD studies revealed that they have face centered cubic structure and have the average grain size of $3.6 \mathrm{~nm}$. From the SEM studies, the average particle size of $\mathrm{CeO}_{2}$ nanoparticles prepared at 24 hours was found to be $63 \mathrm{~nm}$. The UV-visible spectroscopic studies and PL studies 

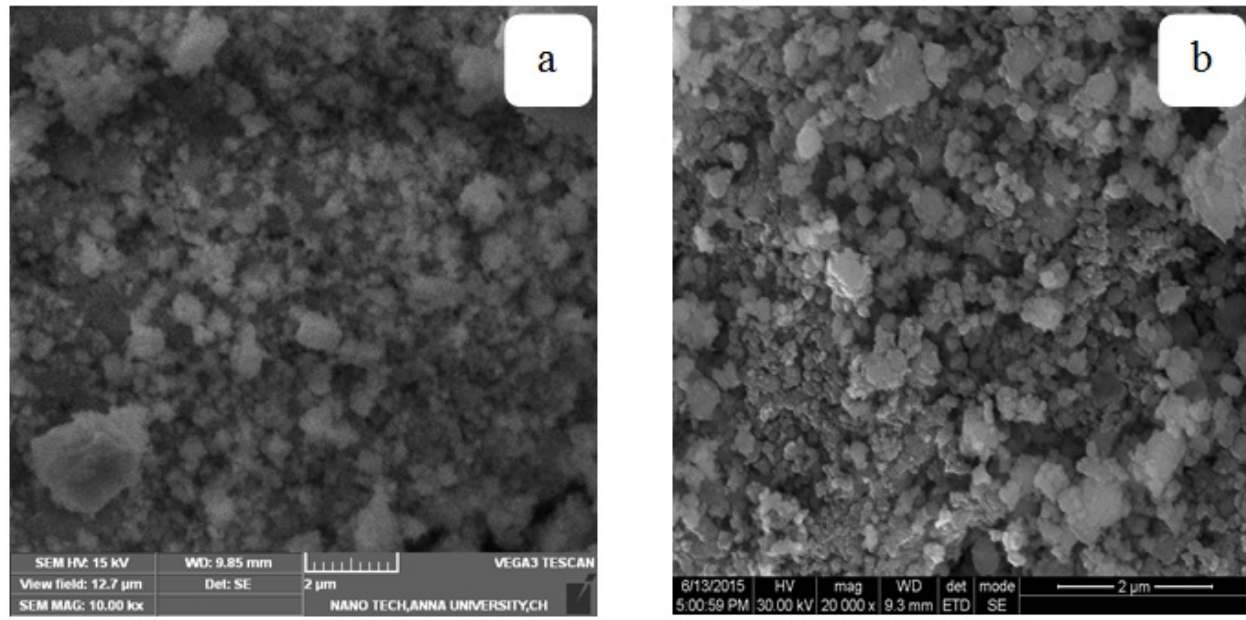

FIG. 4. SEM images of the $\mathrm{CeO}_{2}$ nanoparticles prepared at (a) 24 hours and (b) 12 hours

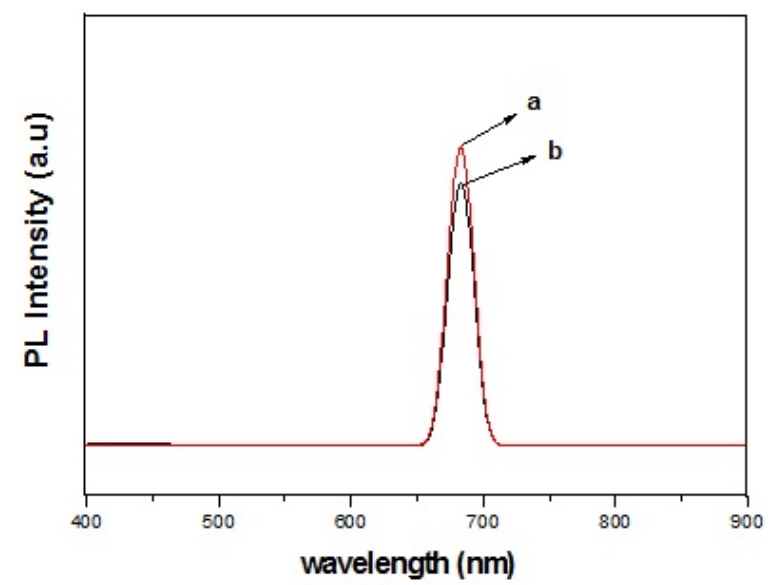

FIG. 5. PL spectra of $\mathrm{CeO}_{2}$ nanoparticles prepared at (a) 24 hours and (b) 12 hours

reveal that the $\mathrm{CeO}_{2}$ nanoparticles prepared at 24 hours have a lower UV cut off wavelength, wider optical transmission range and higher PL emission intensity; i.e. it has better optical properties.

\section{References}

[1] Kang H.S., Kang Y.C., Koo H.Y., Ju S.H., Kim D.Y., Hong S.K., Sohn J.R., Jung K.Y., Park S.B. Nano-sized ceria particles prepared by spray pyrolysis using polymeric precursor solution. Journal of Materials Science and Engineering B, 2006, 127, P. 99-104.

[2] Jayakumar G., Albert Irudayaraj A., Dhayal Raj A., Magimai Antoni Raj D., Daniel Lawrence D. Comparative studies on Cerium Phosphate and Cerium Oxide Nanoparticles. Journal of Chem. Tech Research, 2015, 7(3), P. 1385-1391.

[3] Masui T., Fujiwara K., Machida K., Adachi G. Characterization of cerium (IV) oxide ultrafine particles prepared by reversed micelles. Journal of Chem. Mater, 1997, 9, P. 2197-2204.

[4] Chen H., Chang H. Homogeneous precipitation of cerium dioxide nanoparticles in alcohol/water mixed solvents. Colloids and Surfaces A: Physicochem. Eng. Aspects, 2004, 242, P. 61-69.

[5] Khan S.B., Faisal, Mohammed Rahman M., Jamal A. Exploration of $\mathrm{CeO}_{2}$ nanoparticles as a chemi-sensor and photo-catalyst for environmental applications. Science of the total Environment, 2011, 409, P. 2987-2992.

[6] Wang G., Mu Q., Chen T., Wang Y. Synthesis, characterization and photoluminescence of $\mathrm{CeO}_{2}$ nanoparticles by a facile method at room temperature. Journal of Alloys and Compounds, 2010, 493, P. 202-207.

[7] Bo Liu, Bingbing Liu, Li, Zepeng Li Q, Ran Liu, Xu Zou, Wei Wu, Wen Cui, Zhao dong Liu, Dongmei Li, Bo Zou, Tian Cui, Guangtian Zou. Solvothermal synthesis of monodisperse self-assembly $\mathrm{CeO}_{2}$ nanospheres and their enhanced blue-shifting in ultraviolet absorption. Journal of Alloys and Compounds, 2010, 503, P. 519-524

[8] Kumar E., Selvarajan P., Muthuraj D. Synthesis and characterization of $\mathrm{CeO}_{2}$ nanocrystals by solvothermal route. Journal of Materials Research, 2013, 16, P. 269-276. 